\title{
Electric Vehicles and the Smart Grid: Spatial Modelling of Impacts and Opportunities
}

\author{
Phillip Paevere ${ }^{1}$, Andrew Higgins ${ }^{1}$, George Grozev ${ }^{1}$, Zhengen Ren ${ }^{1}$, Mark Horn ${ }^{1}$ \\ ${ }^{I}$ CSIRO Energy Transformed Flagship, PO Box 56, Highett, VIC, 3190, Australia, Phillip.Paevere@ csiro.au
}

\begin{abstract}
In this paper we present a novel composite methodology for obtaining spatial projections of the impacts and opportunities arising from the integration of plug-in electric vehicles with future smart electricity grids. We link models of future plug-in electric vehicle uptake, travel by household members, household electricity demand, and recharge of electric vehicles. The analysis is disaggregated in each case to a mesh block or local government area level; vehicle usage and household energy demand fluctuate on a hourly, daily and seasonal basis, subject also to the longer-term trends projected for uptake of the new technology. A similarly fine grain is applied with respect to socio-economic variables. The uptake model combines features of choice modelling, multi-criteria analysis and technology diffusion theory; in this case it was applied to four competing technologies (BEV, PHEV, HEV, ICE), and calibration revealed seven major determinants of uptake: performance, annual costs, purchase cost, household income, driving distance, demographic suitability, and risk or inconvenience. The travel model projects likely patterns of vehicle usage and travel duration based on existing patterns of private vehicle usage. The household demand model includes detailed representation of housing type and usage of electrical appliances. The charge-discharge model embodies plausible algorithms for managing household electricity usage in conjunction with electric vehicle batteries. In the paper we describe the various models and report projected impacts of electric vehicles on peak electrical grid loads for the Australian state of Victoria. The impacts are presented on a spatial basis, to the level of individual mesh blocks and network feeders, under a range of energy management scenarios.
\end{abstract}

Keywords: electric vehicle, electric grid, diffusion modelling, travel modelling, household energy

\section{Introduction}

Most of the world's major vehicle manufacturers are currently developing plug-in electric vehicles (EVs) for the mass market. Widespread adoption of these vehicles is anticipated in Australia over the next 30 years [1]. Two types of plug-in EVs are coming to market soon, or are on the horizon: battery-only electric vehicles which run entirely on a battery charged from the grid (BEVs), and plugin hybrid electric vehicles which can run on batteries charged from the grid alone (PHEVs), liquid fuel (petrol), or a combination of both. 
For typical battery sizes and Australian driving patterns, these two EV types may require between $2 \mathrm{kWh}$ and $20 \mathrm{kWh}$ of electrical energy per vehicle from the grid if widely adopted for passenger transport [2]. This represents a significant potential increase in electrical load on the grid which needs to be planned for in the future. Conversely, the electrical energy storage capacity available in electric vehicles, when not needed for transportation, can potentially be harnessed and used to support the needs of the electricity grid at times of high demand or constrained generation.In order to plan for the extra load from EVs, and to understand the impact and opportunities of extra loads and storages on an electricity distribution system with temporally and spatially variable capacity, it is critical to be able to project the magnitude, rate, and location of EV uptake, usage and charging/discharging by consumers at a fine spatial scale. This paper presents a an integrated suite of models (with some case study examples) for estimating the uptake, usage and charging of electric vehicles, and then determining the peak load impacts on individual feeder lines in the electrical distribution system. It is assumed here that EVs are charged only at home ("ondriveway"), thus excluding recharge at places of work, parking stations, or at special recharge stations.

\section{Model Overview}

The integrated modelling approach described here is designed to spatially model the future impacts of EV usage on the electrical grid. The integrated modelling strategy is outlined in diagrammatic form in Fig. 1, and incorporates:

- A Diffusion Model for forecasting EV uptake across an urban area at three-monthly time intervals, given different financial and policy settings, in spatial mesh blocks of around 100 houses

- An EV Travel Model for spatially projecting the likely driving distances and travel durations, and the periods of availability for charging and discharging of EVs, across different parts of an urban area

- An EV Charging \& Discharging Model for projecting hourly energy requirements (x365 days) for a given set of EV travel and charging parameters, in spatial mesh blocks of around 100 houses
- A Residential Energy Model for projecting the hourly residential energy usage (x365 days) across an urban area in spatial mesh blocks of around 100 houses.

\section{EV demand over space \& time}

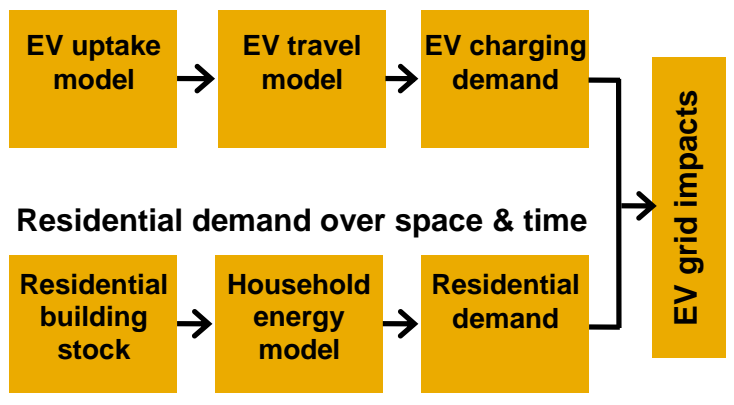

Figure 1: Integrated modelling framework

The suite of models is integrated to enable scenario projections that link spatial projections of EV uptake and usage with the impacts of EV charging and discharging on peak electrical load for individual feeder lines or other sub-networks across the electricity grid. Different scenarios can be modelled to explore a range of potential questions, such as:

- How will EV-related government policies (e.g. purchase rebates) affect EV uptake, EV clustering, and subsequent impacts on electrical grid peak loads?

- How will EV charging/discharging technologies (e.g. Vehicle-to-House) affect charging behaviour and electrical grid peak loads?

- How will electricity pricing arrangements (e.g. time-of-use electricity pricing or capacity pricing) affect potential EV uptake, charging behaviour, and grid impacts?

A brief outline of the various model components is given in the following sections, followed by some case study examples.

\section{EV Uptake Model}

The diffusion model for EV uptake combines features of choice modelling, multi-criteria analysis and diffusion models. The total stock of all vehicles is known over time and the market shares of the respective vehicle technologies are to be estimated. The focus is on choices amongst competing vehicle types under a range of features relevant to buyers' purchasing decisions. A 
household's purchasing decision is made when one of its existing vehicles reaches the end of its lifespan.

Model parameters include the following:

- Housing disaggregated by location and housing type

- The set of competing vehicle types, including BEV, PHEV and diesel

- A planning horizon, modelled at discrete timesteps (30 years at quarterly intervals in this research)

- Expected life span of each vehicle type, in terms of number of time intervals

- Forecast of new households expected to purchase vehicles in each time interval

- Total stock of each vehicle type in each demographic and location category at the beginning of the planning horizon.

The main outputs from the diffusion model are the stocks of each vehicle type for each demographic by location category at each time interval. A detailed description of the model is given in $[5,6]$.

\subsection{EV Uptake Case Study - Victoria, Australia}

Victoria is an Australian state with a population of 5.2 million people (2006) and a residential vehicle stock of 2.21 million. The primary source of information was the Australian Bureau of Statistics (ABS), which defines 9,300 small-area units called census collection district (CCDs) in Victoria, each representing about 250 households. For the present research several CCD-level data categories were posited as key drivers of vehicle choice, notably housing type, housing ownership status, household income category and number of vehicles. These were divided into a small set of categories and the number of households in each combination of categories obtained. The following categories were used:

- Housing type: Detached house, Other

- Ownership: Own (including mortgage), Rent

- Household income: AUD \$0-\$30,000/yr, $\$ 30,000-\$ 75,000 / \mathrm{yr},>\$ 75,000 / \mathrm{yr}$

- Vehicles: 0, 1,2+.

Four different vehicle types were considered: BEV, PHEV, Traditioanl Hybrid (HEV) and Internal Combustion Engine (ICE). Seven criteria were identified as essential drivers for vehicle choice: performance, annual costs, upfront cost, household income, driving distance, demographic suitability, and risk/convenience. Based on the Oliver Wyman Study "E-Mobility 2025" (www.oliverwyman.com), we assumed the annual change in $\mathrm{EV}$ costs to be $-3 \%,-1.5 \%$ and $0 \%$ for Hybrid and ICE vehicles respectively.

For the demographic criteria, an EV demographic suitability score was generated for each location (CCD) in Victoria using several ABS variables for each location. The variables used were: Age (age group categories); Number of residents in the household, Employment (full time, part time, unemployed); Education (high school, diploma, degree etc); Occupation (career categories), and Transport mode (car, train, bus etc.). For each of these variable categories an EV suitability score was allocated based on suitability categories inferred from the survey. A planning horizon of 20 years (2011 to 2030) was used for the case study. The initial vehicle stock was set to the values in the 2006 ABS data, since updated values by CCD are not available until late 2012. For this current report, the initial market share of HEVs was 3\% (2010), and the remaining market share was ICE. For households that do not have a vehicle, we assumed they remained without a vehicle throughout the planning horizon. Our case study is based on a static population and demographic breakdown through to 2031 .

\subsection{EV Uptake Projection - Base Case}

Fig. 2 shows the overall market share of the four vehicle types, calibrated to the scenario in [1]. The large upfront adoption of HEVs is due to the lower risk and costs in 2011. Decreases in these barriers over the planning horizon lead to a gradual increase in the relative significance of barriers in the case of BEVs and PHEVs. Fig. 2 shows the modelled market shares of BEVs and PHEVs for 2030 across the greater Melbourne region, highlighting differences in adoption between rural and urban areas. The main drivers of these differences were driving distance (limited in the case of BEVs), occupation and education. For more local differences, the main drivers were household income and employment status, which were often substantially different in neighbouring suburbs. In Fig. 3 the predicted spatial distribution of vehicle uptake across Victoria for 2030 is shown for all vehicle types. BEV uptake in rural and urban areas differs greatly, with PHEVs having the greatest impact in peri-urban areas. 


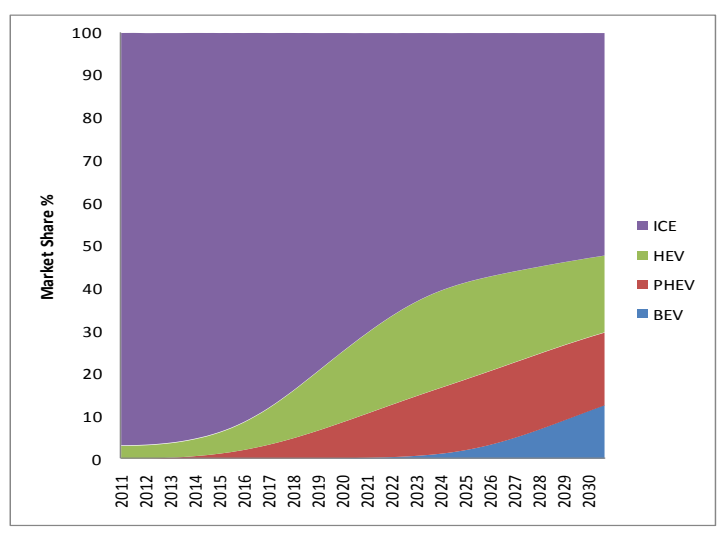

Figure 2: Overall market share trend from 2011-2030

The average modelled uptake of PHEVs was $12.7 \%$ (see Table 1), ranging from $7 \%$ in rural CCDs to $22 \%$ in urban areas. Although the relative numbers of ICE vehicles is projected to decline substantially over 2011-2030 (Fig. 2), their market share is still dominant when viewed geographically (see Fig. 4), due to the much greater land area of rural as against urban CCDs.
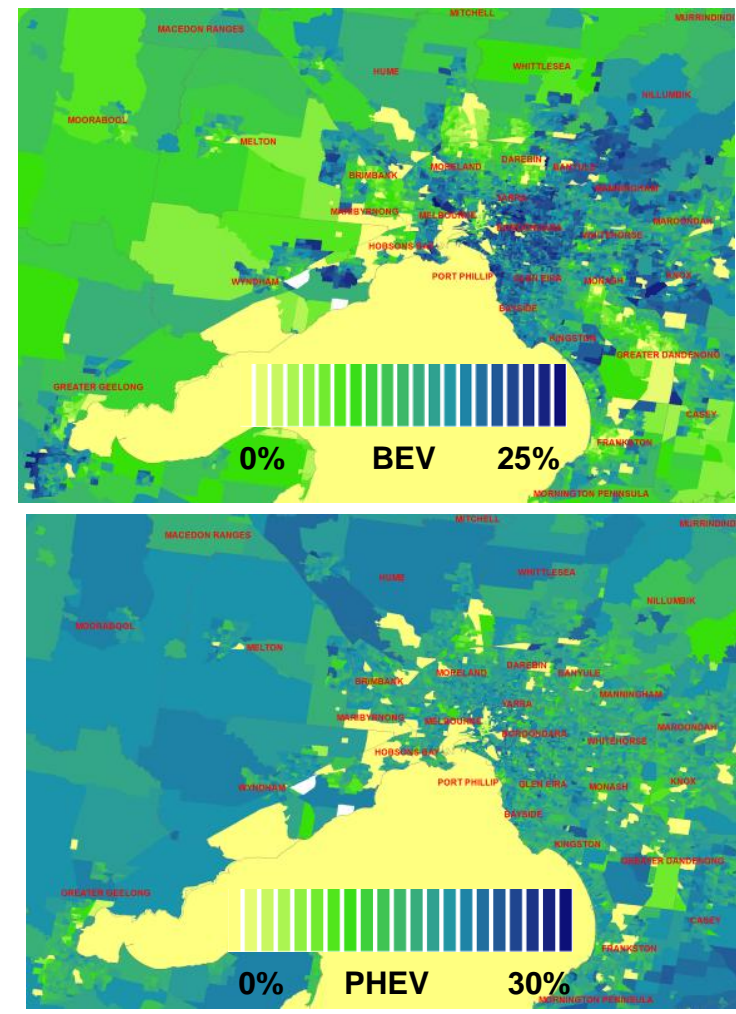

Figure 3: Shares of BEVs and PHEVs at 2030 at the suburb-scale for metropolitan Melbourne

\subsection{Policy analyses}

The diffusion model was used to investigate possible policies designed to promote uptake of EVs. In recent years several Australian governments at state and federal levels have used incentives, in the form of financial rebates to upfront costs, to accelerate the uptake of solar Photvoltaic $(\mathrm{PV})$ and solar hot water systems $[1,7]$. No such program, however, has yet been applied to EVs.

The following hypothetical scenarios were studied:

- Rebates of \$7,500: 2010 to 2030

- Rebates of \$7,500: 2020 to 2030

- Rebates of 25\% (max \$8500): 2010 to 2030

- Rebates of 35\% (max \$10000): 2010 to 2030

- Feebate of 4\%, 2015 to 2030

- Feebate of $2 \%$, increase by $2 \% / \mathrm{yr}$

- Time of Use annual incentive, $\$ 150 / \mathrm{yr}$

- Vehicle to Grid incentive $\$ 1,300$ in 2012, reducing to $\$ 350$ in 2025

- Common cost metric (CCM).

Rebates and time of use incentives apply to BEV and PHEV vehicles, whilst feebates (e.g. increased registration fees) apply to ICE vehicles. Time-ofuse and vehicle-to-grid incentives are annual rebates provided to owners of BEVs and PHEVs. A CCM is a non-financial incentive that provides consumers with information on the whole of life (upfront and future) cost of the vehicle, so as to reduce reliance on upfront cost as a decision point for purchase. CCM is implemented in the diffusion model by increasing the familiarity measure for BEVs and PHEVs by 10 years.

For each scenario, we calculated the total cost to the government. Table 1 shows a general trend of BEV and PHEV uptake increasing with the size of the financial incentive; however, the timing of the incentive is crucial to its efficiency. By introducing the $\$ 7,500$ rebate in 2020 instead of 2010, the total cost was reduced by over $30 \%$ with only a small decrease in the market share of BEV. Our analysis suggests that the common cost metric is an excellent alternative to expensive rebates as a means of accelerating adoption of EVs. This basic analysis can be extended to include combinations of incentives introduced at different times. 
Table 1. Market share (\%) at 2030 for each scenario

\begin{tabular}{lllllc}
\hline Scenario & BEV & PHEV & HEV & ICE & Cost (\$ billion) \\
\hline Base & 12.7 & 21.3 & 22.0 & 44.0 & \\
Rebates of \$7,500 & 22.9 & 24.1 & 20.0 & 33.1 & 14.8 \\
Rebates of \$7,500: 2020 to 2030 & 23.1 & 23.4 & 20.0 & 33.6 & 9.4 \\
Rebates of 25\% (max \$8,500) & 20.8 & 24.1 & 20.1 & 35.1 & 14.6 \\
Rebates of 35\% (max \$10,000) & 23.3 & 27.2 & 19.8 & 29.7 & 20.7 \\
Feebate of 4\%: 2015 to 2030 & 12.7 & 21.3 & 22.1 & 43.9 & $1.2^{\#}$ \\
Feebate of 2\%, increase by 2\%/yr: & 12.9 & 21.5 & 22.3 & 43.4 & $2.9^{\#}$ \\
Time of Use annual incentive: & & & & & \\
\$150/yr & 14.0 & 21.2 & 21.5 & 43.3 & 4.9 \\
V-G smart charging: 2015-2025 & 15.7 & 21.1 & 21.0 & 42.3 & 12.7 \\
Common Cost Metric & 21.6 & 22.5 & 22.6 & 33.3 & \\
\hline
\end{tabular}

${ }^{\#}$ Cost to consumers
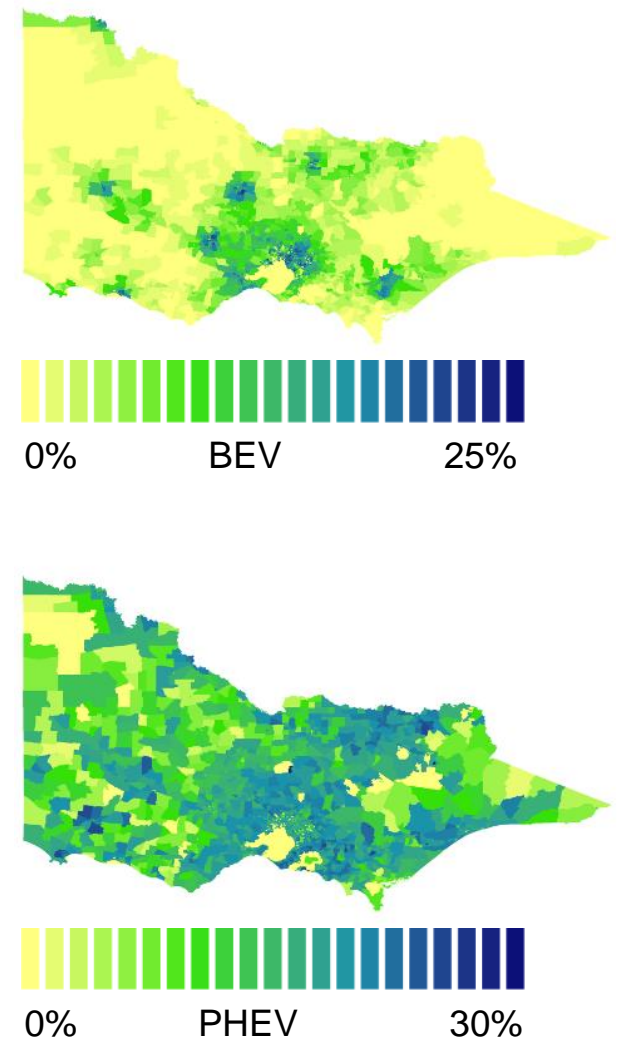

Figure 4a: BEV \& PHEV shares, Victoria, 2030.
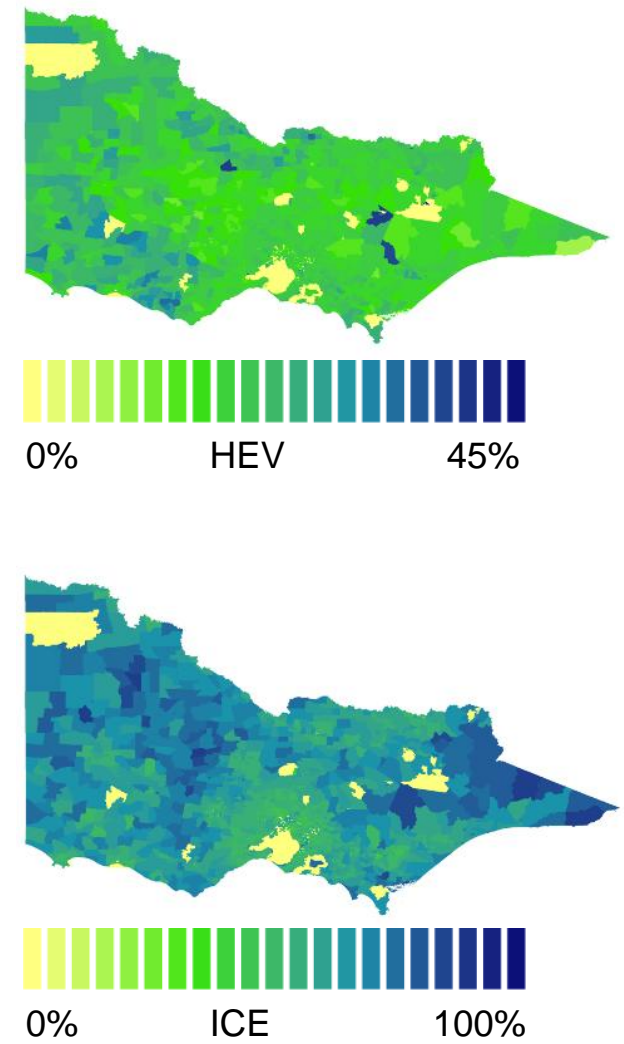

Figure 4b: HEV and ICE shares, Victoria, 2030. 


\section{BEV Travel Model}

The model of BEV travel behaviour is based on data from a Victorian State government activity survey (VISTA), and data on traffic volumes provided by the agency responsible for main roads (VicRoads). A geographical view of travel intensity is essential when studying BEV impacts because BEV usage is highly variable in time and space, depending on the home location of the $\mathrm{BEV}$, local demographics, and proximity to activity centres and to other transport options. The travel model treats existing travel patterns (from VISTA) as a template for BEV usage, and introduces temporal fluctuations based on traffic intensities (from VicRoads data). Implementation of this approach has required some degree of statistical refinement due to the small size of VISTA samples at 'Statistical Local Area' (SLA) geographic units which are larger than CCDs .

The travel model provides estimates of BEV behaviour (e.g. average length and frequency of off-driveway journeys, by time of day); when combined with the uptake estimates, these yield several indicators of BEV activity (e.g. distance travelled, numbers of journeys, and numbers of vehicles at home at any given time), disaggregated by location, by time of day, and by date. Some summary measures of travel behaviour for two geographical regions are presented in Fig. 5.

\section{Residential Energy Model}

The Residential Energy Model is used for projecting the hourly residential energy usage (x365 days) across an urban area in spatial mesh blocks of around 100 houses. This is necessary to understand the impacts that BEV charging and discharging will have across the electricity network at specific times of the day.

The Residential Energy Model is a physics-based bottom-up model that works by aggregating individual household energy consumption (simulated by the recently developed AusZEH energy model $[9,10])$ to blocks of housing using recent Census data and other available data sources. The total energy consumption of housing includes space heating and cooling, water heating, lighting and other appliances, which were estimated by considering building construction and materials, occupant number and behaviour, and local climates. To estimate hourly energy consumption, six potential occupant profiles were proposed for individual houses. Four family types (a couple with children, a couple, a single parent with children and other) and three categories of occupancy (e.g. occupied whole day, half day and evening only) were considered for a block of housing. The proposed method has been validated using actual energy consumption at levels of individual households [11], and a block of housing stock (at CCD and State levels) [12].

This tool could provide insight into impacts of new technologies, building regulations and policies on housing stock energy consumption at local (CCD) or state level, and useful information on peak demand and total energy consumption for policy makers and grid management.
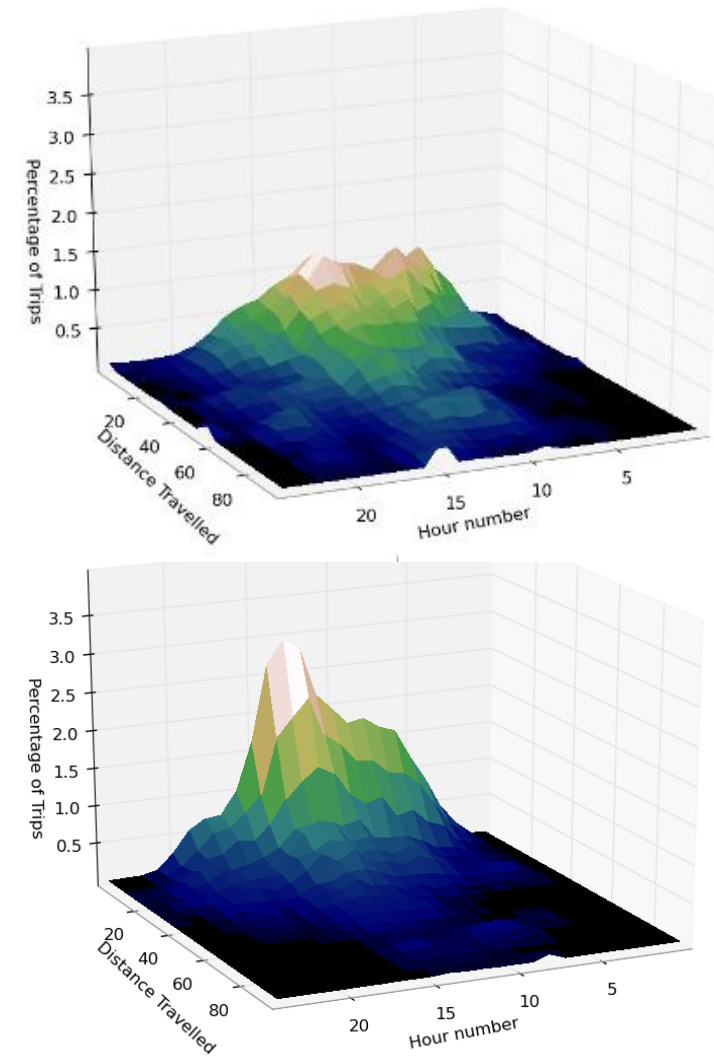

Figure 5: Travel model output - Arrival time and distance travelled probability surfaces for two different geographical regions. 


\section{EV Charge \& Discharge Model}

The EV Charging \& Discharging Model is used to project hourly energy requirements (x365 days) for a given set of EV travel and charging parameters, in spatial mesh blocks of around 100 houses. Four possible and one testing charging mode were identified and modelled in this study. They related to the timing and rate of charging and also to an option of grid support where a car battery is used to provide energy to the house/electricity grid in peak electricity demand periods. These charging \& discharging modes are:

- Demand charging

- Demand charging and vehicle to house (V2H) discharging

- Off-peak charging

- Off-peak charging and V2H discharging

- Equally spread charging (testing mode).

In demand charging mode a BEV is plugged to the electricity grid (at home) and begins charging its battery immediately after the car arrives at the driveway at home. The battery is charged at constant rate until fully charged. In off-peak charging mode a BEV begins charging its battery during a specified off-peak period if available at the driveway. In V2H discharging mode a BEV battery is used to support the electricity grid during a specified peak period, keeping above minimum discharge level. Fig. 6 shows EV charging profiles by time of day for two scenarios at CCD level - demand charging and off-peak charging with V2H discharging. The upper diagram shows the projected load profiles for different parts (CCDs) of Melbourne, under a demand charging scenario where EVs plug-in and fill battery $(3 \mathrm{~kW})$ immediately on arrival at home. The higher-value load curves are for areas in the city where there is a high uptake of EVs plus a high travel demand. The profile shape indicates the relative numbers and travel distances of vehicles arriving home from different activities $(10 \mathrm{am}=$ school drop-off; 3-4 $\mathrm{pm}=$ school pick-up and daytime activities; 5-9 $\mathrm{pm}=$ commuters; $10 \mathrm{pm}-2 \mathrm{am}=$ evening activities). The lower diagram shows charging ( 3 $\mathrm{kW})$ and discharging $(2 \mathrm{~kW})$ load profile under a scenario where the EV delays charging until offpeak periods and discharges energy back into the grid at peak periods, subject to limits on battery capacity and the need to satisfy household travel requirements, as determined by the travel model.
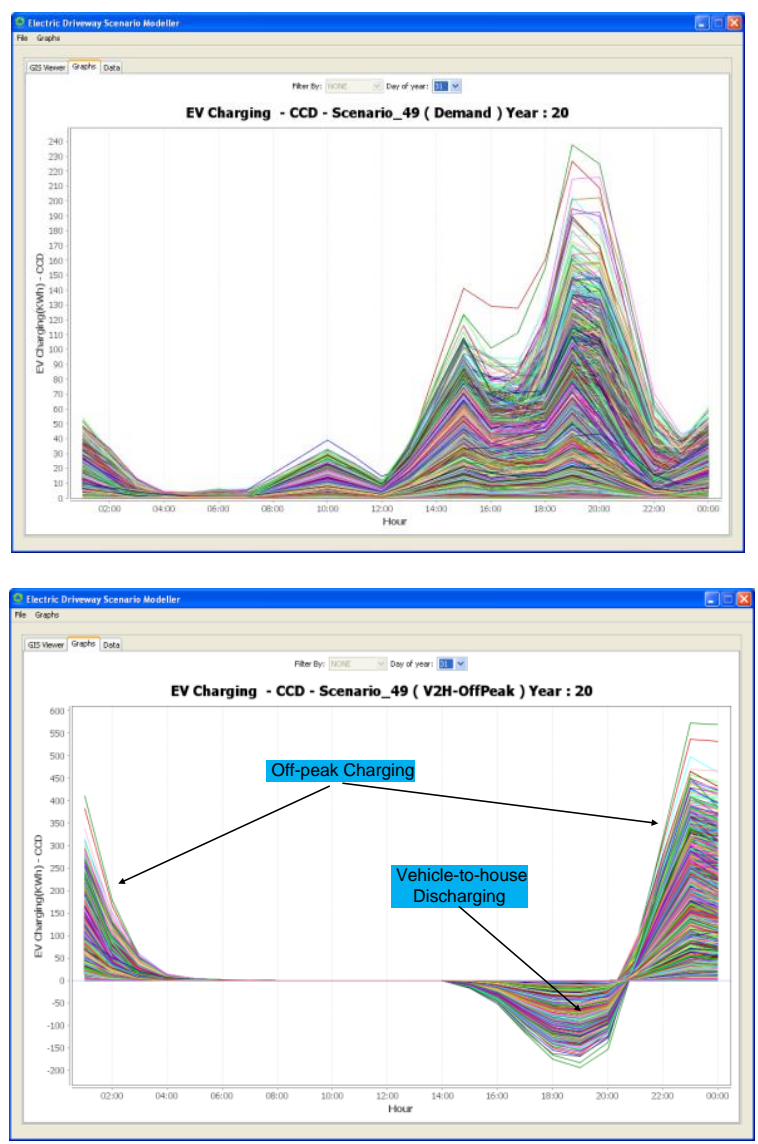

Figure 6: EV charging profiles by time of day and location for two scenarios at CCD level: Demand charging (upper) and Off-peak charging+V2H (lower).

\section{Grid Impacts Analysis}

The Models described above are combined to spatially model the future impacts of EV usage on the electrical grid, based on spatially projected EV uptake rates, spatially distributed travel patterns, and charging (and discharging) scenarios, and the spatially projected residential energy demand. An example of this application is given in Fig. 7, which shows the impacts of EV charging on the grid on a particular hour, on a hot summer day in the year 2030 in metropolitan Melbourne, Victoria. The left hand diagram in Fig. 7 spatially projects the percentage increase in household peak electrical load when EVs are charged on demand (as soon as they arrive home). The lower diagram in Fig. 7 shows, spatially, the changes in peak load under a scenario where the EV delays charging until off-peak periods and discharges energy back into the grid at peak periods, subject to 
limits on battery capacity and the need to satisfy household travel requirements, as determined by the travel model. The scenario modelled is an extreme example, which shows that in some areas of the city, at this particular time of day, the increase in peak load could be in the order of $10-20 \%$. This type of analysis allows pinpointing of the 'hot-spots' on the electrical grid under different charging and discharging scenarios, and will assist governments and industry in assessing the costs and benefits of different EV charging incentives, policies, regulations and technologies.
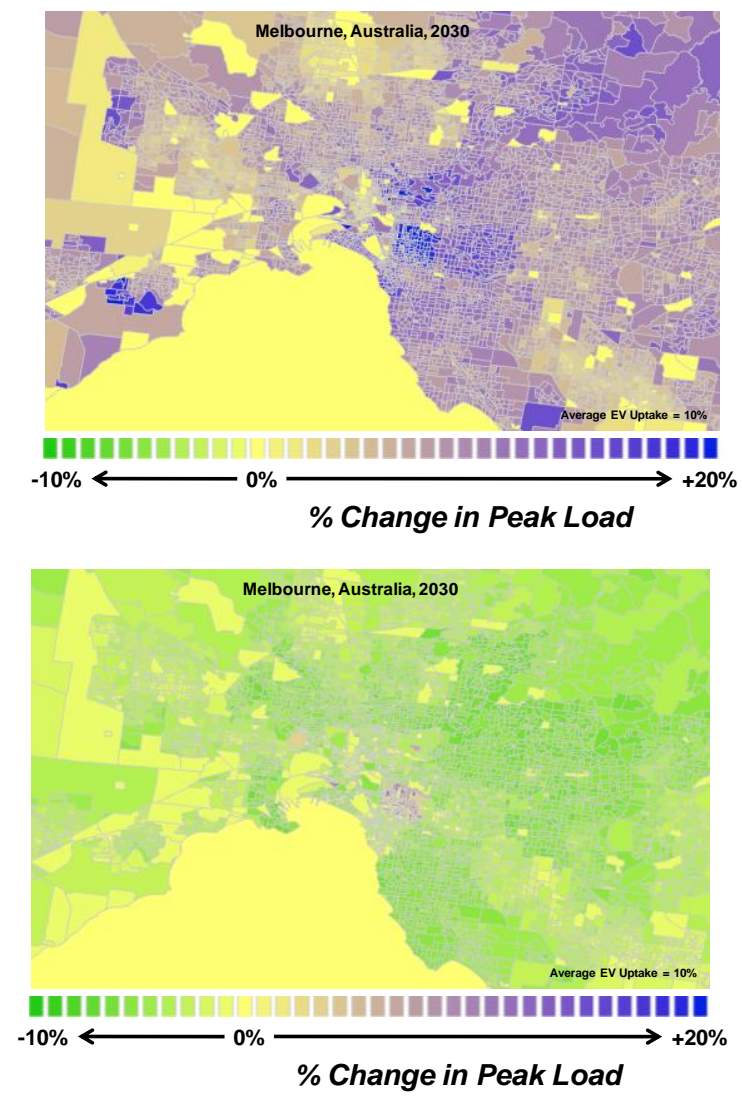

Figure 7: Spatially projected impact of different EVgrid integration scenarios on electrical grid peak load in metropolitan Melbourne, Australia.

\section{Summary and Conclusions}

In this paper we report on successful implementation of a composite modelling framework comprising an innovative diffusion model and models of travel and household energy usage. This framework is designed to estimate the market share, travel patterns and grid impacts of BEVs across a landscape of heterogeneous consumers. The combination of fine geographical and demographic granularity allows adoption and usage rates to be assessed at a sub-precinct level. This provides a useful capability for energy providers to better understand capacity constraints across their electricity grid, allowing for variation in uptake and usage of BEVs at different locations. A case study of Victoria for the period 2011 to 2030 estimated uptake of BEVs and PHEVs, alongside HEVs and ICE vehicles. The fine spatial resolution of the study revealed notable differences at local and regional levels, attributable to driving distance, employment status and household income. By testing the uptake model on scenarios of government financial rebates and BEV range improvements, we demonstrated a powerful capability to inform or optimise various government policy schemes targeted towards increasing adoption of BEVs at minimal cost.

An essential accompaniment to the uptake modelling was the modelling of travel behaviour to a level of disaggregation in space and time to match the modelling of residential electrical loads. This required some ingenuity, both in the application of travel activity data and in the use of traffic data to estimate temporal patterns in travel activity. Possible extensions include study of scenarios involving recharge at locations such as parking stations and other off-driveway locations, and elaboration of the travel model in light of projected future changes in land use and travel behaviour. Another important avenue for further research lies in the development of algorithms for efficient household energy management, along the lines of the model presented in Section 6.

\section{Acknowledgments}

The authors thank their CSIRO colleagues Dr John Page and Mrs Cheryl McNamara for their assistance in data processing and visualisation. Thanks are also due to the following individuals for their assistance in the provision of data: Jonathan Fam and Roger Clarke of VicRoads, and Stephen Roddis and Steven Herbert of the Victorian Department of Transport, and the following funding Partners: Victorian Government and SP-Ausnet.

\section{References}

[1] P. Graham, L. Reedman, and F. Poldy, Modelling of the future of transport fuels in Australia, Report IR1046 to the Future Fuels Forum. www.csiro.au, 2008

[2] J. Usher, C. Horgan, C. Dunstan, P. Paevere, CSIRO Electric Driveway Project: 
Technical, Economic, Environmental \& Institutional Assessments Phase 1 Report, Prepared for Australian Commonwealth Scientific and Industrial Research Organisation (CSIRO), by the Institute for Sustainable Futures, UTS: Sydney, 2011

[3] Z. Lin, and D. Greene, Who will more likely buy PHEV: A detailed market segmentation analysis, The 25th World Battery, Hybrid and Fuel Cell Electric Vehicle Symposium \& Exhibition, Shenzhen, China, 2010

[4] J. Axsen, D.C. Mountain and M. Jaccard, Combining stated and revealed choice research to simulate the neighbour effect: The case of hybrid-electric vehicles, Resource and Energy Economics,31(2009), 221238

[5] A. Higgins, G. Foliente, and C. McNamara, Modelling intervention options to reduce GHG emissions in housing stock - a diffusion approach, Technological Forecasting \& Social Change,78(2011), 621-634

[6] A. Higgins, P. Paevere, J. Gardner, and G. Quezada, Diffusion of competing vehicle options across a landscape of heterogeneous consumers, Technological Forecasting \& Social Change, (2012 under review)

[7] Australian Government. Renewable Energy Bonus Scheme - Solar Hot Water Rebate. Department of Climate Change and Energy Efficiency.

http://www.climatechange.gov.au/governm ent/programs-and-rebates, 2010

[8] C. Dunstan, J. Usher, K. Ross, L. Christie, P. Paevere, Supporting Electric Vehicle Adoption in Australia: Barriers and Policy Solutions, An Electric Driveway Project Report prepared for Australian Commonwealth Scientific and Industrial Research Organisation (CSIRO), by the Institute for Sustainable Futures, UTS: Sydney, 2011

[9] Z. Ren, G. Foliente, W. Chan, D. Chen and M. Syme, AusZEH design: software for low-emission and zero-emission house design in Australia, In: Proceeding of Building Simulation 2011, Sydney, 14th16th November, 2011

[10] Z. Ren, D. Chen and X. Wang, Climate change adaptation for Australian residential buildings. Building and Environment 46(2011), 2398-2412

[11] Z. Ren, G. Foliente, D. Chen, M. Ambrose and P. Paevere, A physics-based model for predicting housing energy consumption and associated greenhouse gas emissions in Australia, a paper submitted to Building Simulation, January 2012

[12] Z. Ren, P. Paevere, and C. McNamara, Predicting energy consumption of housing stock at Census Collection District level by a physically-based model, a paper submitted to Energy Policy, March 2012

\section{Authors}

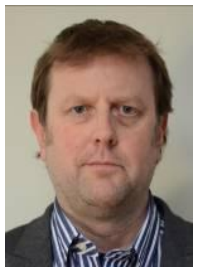

Dr Phillip Paevere is the leader of the Urban Systems Program in CSIRO, where he directs a portfolio of multidisciplinary research spanning the domains of energy, climate change, and the built urban environment. $\mathrm{He}$ has Bachelors $(\mathrm{H} 1)$ and $\mathrm{PhD}$ degrees in Engineering from the University of Melbourne.

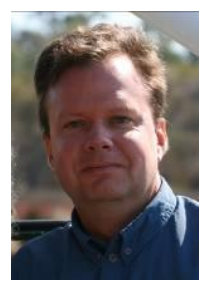

Dr Andrew Higgins is an operations research expert and has 15 years experience in developing optimisation and forecasting applications in energy, water, agriculture and transport. Andrew received his $\mathrm{PhD}$ from Queensland University of Technology.

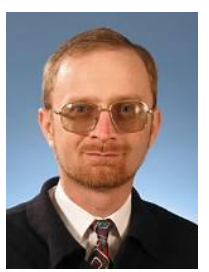

Dr George Grozev is a research group leader, within Urban Systems Program, CSIRO. With a background in modelling, optimisation and simulation, he is working on sustainable development issues of energy markets (electricity and gas) and energy infrastructure in Australia.

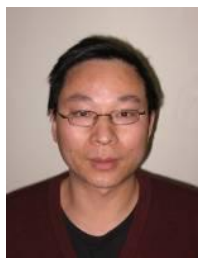

Dr Zhengen Ren is a thermal energy expert with more than twenty years' experience of energy conservation and modelling development for building energy performance and indoor environment.

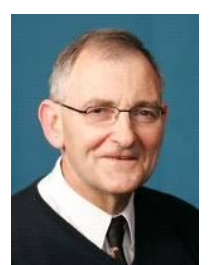

Mr Mark Horn has extensive experience in modelling transport and electricity supply systems and in managing consultancy projects. He has professional degrees in architecture and city planning (B.Arch. Hons., M.C.P.). 